\title{
THE FIRST ARCH SYNDROME
}

\author{
BY \\ J. McKENZIE \\ From the Department of Anatomy, University of Aberdeen
}

(RECEIVED FOR PUBLICATION FEBRUARY 17, 1958)

\begin{abstract}
Although disfiguring abnormalities of the face have been a problem to the plastic surgeon for many years and the accompanying embarrassment and morbidity have equally exercised the ingenuity of the psychiatrist, there is yet neither satisfactory treatment nor an adequate mask to shield the sufferer. Accordingly, the search for the cause and possible means of prevention has been intensively pursued for many years.

From an examination of the clinical features, anatomy and embryology of the following anomalies of the head and neck, it is clear that all arise from abnormal development of the first visceral arch and should be regarded as comprising a "first arch syndrome': (a) The Treacher Collins syndrome or mandibulofacial dysostosis; (b) Pierre Robin syndrome (hypoplasia of the mandible with glossoptosis); (c) mandibular dysostosis; (d) deformities of the external and middle ear; $(e)$ congenital deafmutism; $(f)$ cleft lip and cleft palate; $(g)$ hypertelorism; $(h)$ a recently described syndrome exhibiting congenital deafness and hypertelorism.
\end{abstract}

Treacher Collins Syndrome. Berry (1889) and Treacher Collins (1900) each described patients showing a small notch at the junction of the outer third and inner two thirds of each lower eyelid, associated with 'an unusual want of prominence of the malar bones'. Subsequent writers, de Lima and Montiero (1923), Isakowitz (1927), Lockhart (1929), Waardenburg (1932), Herman (1936), van Linnt and Hennebert (1936), McEnery and Brennemann (1937), Debusmann (1940) and Mann (1943), added to the syndrome agenesis of the mandible, poorly developed eyelashes in the medial part of the lower lid, abnormalities of the external and middle ear, deafness, drooping of the outer canthus giving an antimongoloid obliquity of the palpebral fissures, microphthalmos and a marked hereditary trait. Franceschetti and Klein (1949) recognized the association of those features, proposed the term mandibulofacial dysostosis and attributed the condition to 'an inhibitory process occurring towards the seventh week of embryonic life and affecting the facial bones deriving from the first visceral arch. . . . The syndrome is of genic origin and is transmitted in an irregular mode ... dealing with an unstable gene of occasional pleotropic, polyphaenic effect'. Hövels (1953a) also reviewed the subject and (1953b) claimed that these first arch anomalies resulted from maldevelopment of the head neural crest.

Pierre Robin Syndrome. In the newborn, hypoplasia of the mandible associated with a tendency for the tongue to block the pharynx (glossoptosis) has attracted attention because of the attendant feeding difficulties, choking fits and emaciation. Apart from their occurrence in the Treacher Collins syndrome, these features may be present alone, comprising the Pierre Robin syndrome. As described by Lenstrup (1925), Ely and Farber (1930), Davis and Dunn (1933), Robin (1934) and Lapage (1937), the condition shows a remarkable tendency to spontaneous improvement; this, and the fact that the symphysis menti is nearly vertical and the angle of the mandible nearly a right angle (Walker, 1956), have diverted attention from the purely teratogenic theory of origin to that expressed by Llewellyn and Biggs (1943), viz., that the micrognathia is purely a mechanical effect produced by the pressure of the chin against the sternum in the vertex position of the foetus; these authors went even further: they claimed that the frequent complication of cleft palate may be the result of the tongue being pushed back into the mouth and preventing the fusion of the palatal processes.

Mandibular Dysostosis. Obviously, micrognathia may occur in varying degrees, some so slight as to be unnoticed, and it is probably only in cases with a 
disproportionately large tongue interfering with respiration and feeding that the condition calls for attention. Nager and Reynier (1948) did not mention glossoptosis when they described mandibular hypoplasia in association with defects of the ear; they called this syndrome mandibular dysostosis.

Deformities of the External and Middle Ear. These require no description here. Wilson (1955) in his classification observes that the more severe the defect of the auricle the more likely the involvement of the meatus, that accessory auricles and pre-auricular fistulae tend to be hereditary and that in anomalies involving the external and middle ear the most frequently involved ossicles are the malleus and the incus.

Congenital Deafmutism. Dealing with abnormalities of the inner ear, Wilson (1955) states that they are 'inextricably mixed up with deafmutism', while Altmann (1950) describes the pathological changes found in the cochlea of two deaf mutes; there appears to be great difficulty in differentiating pathological from congenital abnormal alterations. McKenzie (1958) has shown, from audiometric examination of five cases of congenital deafmutism, that the condition is caused by an abnormality of the middle ear. On this account, and because of its association with congenital anomalies of the first visceral arch, the probability is that congenital deafmutism, also, arises from the same initial developmental fault.

Cleft Lip and Cleft Palate. Here the most likely cause is a failure or disturbance in the development of either the maxillary or frontonasal process, usually the maxillary, causing sufficient inhibition of growth to prevent approximation of these processes at the scheduled time. In cleft lip it is worth noting how the ala or alae and dorsum of the nose succeed, by dint of appreciable flattening or 'spreading', in bridging the difficult gap between the nasal process and the maxilla. Accompanying congenital lesions include anomalies of the ear, deafness, microphthalmos and asymmetry of the mandible.

Hypertelorism. Ocular hypertelorism is a term coined by Grieg (1924) to describe the unusually wide interval between the medial canthi in two cases which he was fortunate to dissect. The following features may be seen in his illustrations: there is a wide nasal aperture, its roof formed of greatly expanded nasal bones with a small sutural bone between them; the maxillae are slender and seem stretched to their utmost to fulfil their duty of bounding the nasal aperture and, even allowing for the absence of teeth and consequent bone resorption, they are undoubtedly hypoplastic; the angle between the axes of the orbits is increased, hence the patient's difficulty when looking at near objects stereoscopically; the zygomatic bones may not be quite up to the mark developmentally but at least they have the distinction of being able to support the skull (less the mandible) when it is set on the table; in the base of the skull the unusual feature is the great width of the cribriform plates of the ethmoid and of the body of the sphenoid including the hypophyseal fossa, with persistence of the craniopharyngeal canal, the original track of Rathke's diverticulum; the greater wing of the sphenoid is narrow and no greater in size than the lesser wing, the deficiency in the temporal region resulting from this anomaly and from the rather poor development of the temporal squama being compensated for by sutural bones. Greig believed that the developmental fault lay in that portion of the cartilaginous base of the skull which gives rise to the ethmoid and the body, lesser wings and medial half of the greater wings of the sphenoid.

Deafmutism with Hypertelorism. Fisch andRenwick (1956) drew attention to the combination of these conditions when they appealed for help in tracing cases characterized by the following features: (a) lateral displacement of the inner angles of the eyes, (b) a broad nose root, $(c)$ different colours of the right and left eyes, $(d)$ white forelock and $(e)$ congenital deafness.

\section{Case Histories}

The cases described below illustrate conditions comprising the first arch syndrome.

Case 1. A.R. (Figs. 1 and 2) was described and discussed by McKenzie and Craig (1955), the essential points being the receding chin with a large tongue held towards the back of the mouth, the palpebral fissures slanting downwards at the outer ends, the lower eyelid bent at the junction of the inner two thirds and outer third, eyelashes scanty in the medial two thirds, hypoplasia of the malar bones and low set ears. The child died at the age of 10 weeks from feeding difficulties and cyanotic attacks. The trunk was normal at autopsy; dissection of the head revealed absence of the zygomatic bone and the zygomatic process of the temporal bone, the maxilla completing the orbital margin and providing attachment for the masseter (Fig. 3); the squamous temporal was very small, the deficiency made up by surrounding bones and by an extra bony plaque. In the mandible the body was foreshortened, the coronoid process everted and the head elongated anteroposteriorly; the articular eminence was absent. In the ear, the incus and stapes were normal. There was no parotid gland but the facial musculature was 

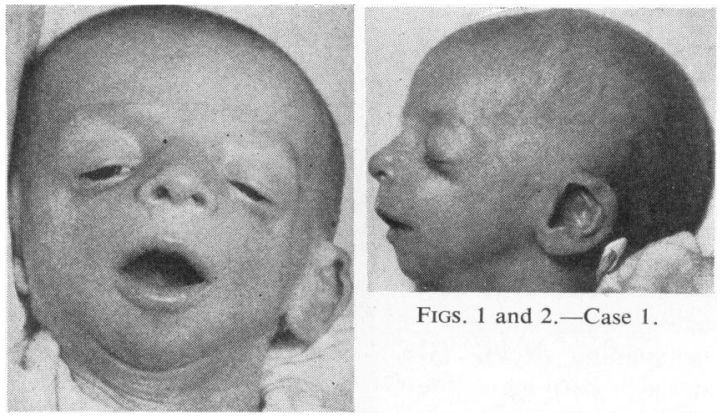

Figs. 1 and 2.-Case 1.

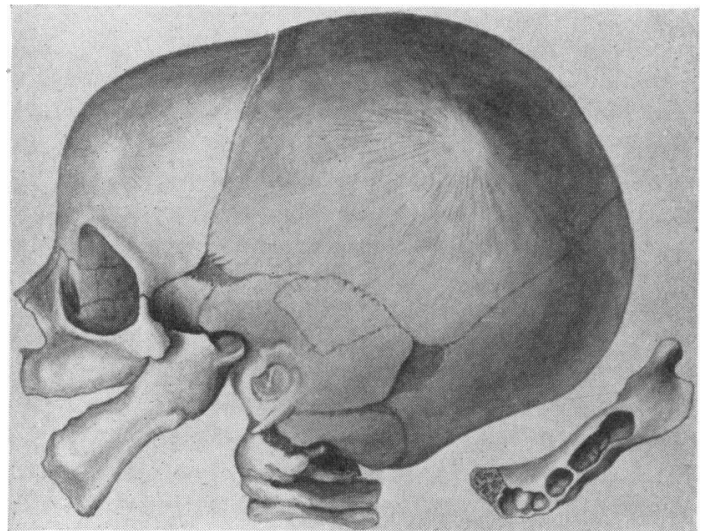

FIG. 3.-Case 1. Lateral view of skull.

well developed. The maxillary artery supplied inferior dental, posterior superior dental and middle meningeal branches but petered out before it reached the pterygomaxillary fissure; the lower surface of the palate was supplied by the posterior superior dental artery while the nose received blood from a vessel which arose from the maxillary artery near the inferior dental artery, ran along the lower head of the lateral pterygoid muscle, entered the pterygopalatine fossa from behind and finally ran up to and through the sphenopalatine foramen into the nose. The infra-orbital artery was a branch of the ophthalmic artery.

Case 2. In G.A., aged 17 (Fig. 4), the only obvious anomaly of the head is the markedly receding mandible which reveals on the lateral radiograph (Fig. 5) an infantile appearance, namely short anteroposteriorly, an unusually wide angle, a short ascending ramus and a body lacking in depth and comprising chiefly alveolar bone; the maxilla, also, would be unusually small without its alveolar part. In the occipitomental view (Fig. 6), there is a bony deficiency in both zygomatic arches. At the age of 3 , he began to complain of pain about his knees on exercise and within a year or so it was noticed that he was becoming knock-kneed. By the age of 7, radiographic examination showed anterior bowing of the femoral shafts with haziness of the bone structure around their lower epiphyses suggesting a slight degree of rickets. Two years later there was an equally marked but opposite curvature of the upper ends of the tibiae. The lower ends of the forearm bones were also curved due to abnormal epiphyseal growth. Osteotomies in the lower limbs at the age of 15 to correct the deformities have been complicated by non-union. Renal rickets and other metabolic disorders have all been excluded. He has one sister 21 years older than himself.

Case 3. M.N., aged 9 (Figs. 7 and 8), presents marked asymmetry of the face due to absence of the ascending ramus of the mandible on the left side and absence of the left zygomatic bone with a poorly developed maxilla; the left auricle is represented by several small tubercles lying further forward than normal and the left external auditory meatus is absent. Hearing is good but probably only with the right ear. A moderate degree of hypertelorism is present, the frontonasal angle flattened, the tongue musculature poor on the left side and the palatal

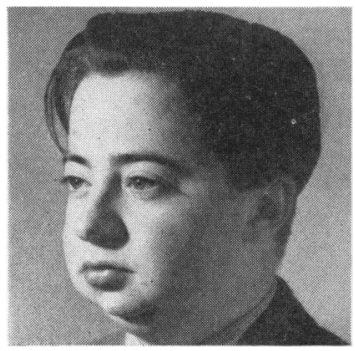

Fig. 4.-Case 2.

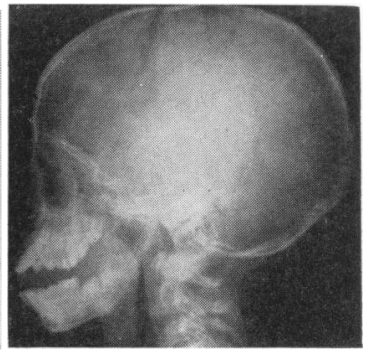

Fig. 5.-Case 2. Lateral radiograph.

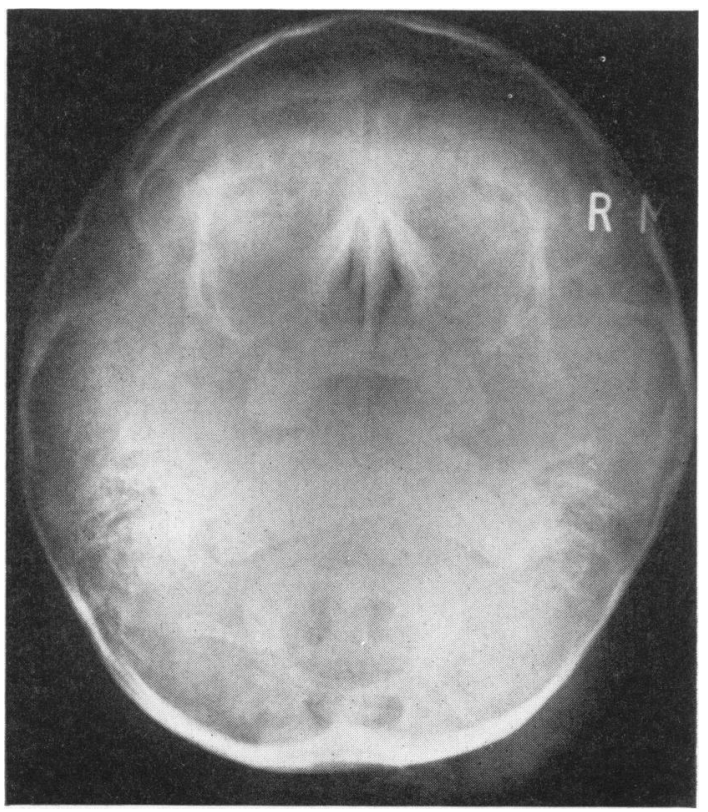

FIG. 6.-Case 2. Occipitomental radiograph. 


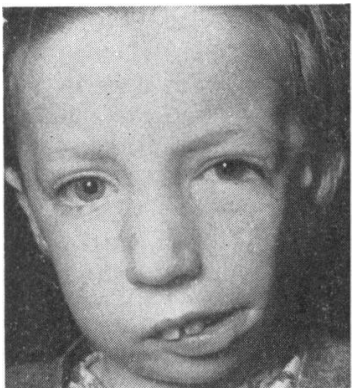

FIG. 7.-Case 3.

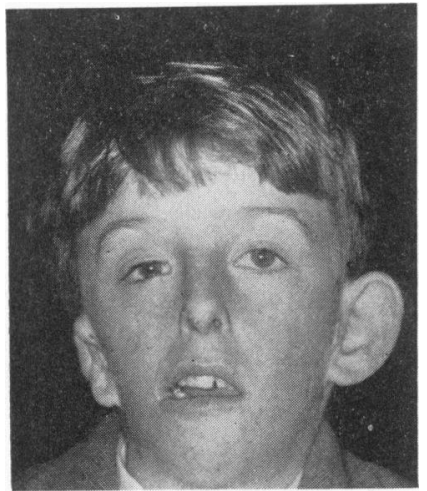

Fig. 9.-Case 4.

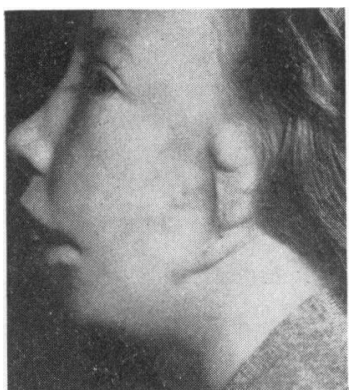

Fig. 8.-Case 3.

arch high but intact.

Case 4. A.G., aged 10 (Fig. 9), shows hemiatrophy but no bony deficiency of the jaw on the right side, irregularity of the oral mucocutaneous junction and hypoplasia of the right cheek with drooping of the outer canthus.

Case 5. A.A.M., aged 1 year, was recognized at birth as a very feeble, hypotonic, listless child with depressed bridge of nose, widely set eyes, simple low-set ears, flattened left forehead and flattening of the back of the skull on the opposite side; the soft palate was cleft and there was an obvious twist of the mandible, the tip of the chin being pushed over to the right side (Fig. 10). There has been considerable improvement since then; now it is difficult to identify the deformity of the mandible (Fig. 11) but the depressed, excessively wide bridge of the nose is still present with flattening of the bony orbital margin. Her weight as well as mental and physical development are all poor, feeding difficulties not entirely due to cleft palate restricting her progress.

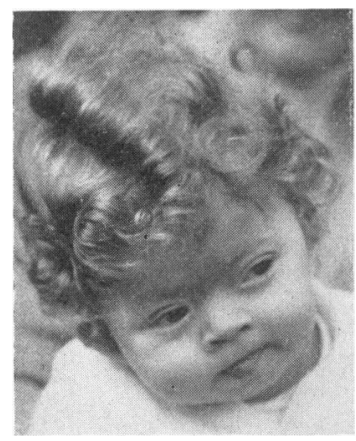

FIG. 10.-Case 5.

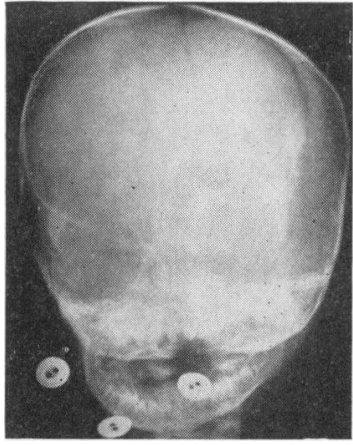

FIG. 11.-Case 5. Radiograph of skull.
Case 6. In A.M. (Fig. 12), much of the conjunctiva is exposed by the S-shaped lower lids which are atrophic and without eyelashes in their medial two thirds. The bilateral defect of the zygomatic bone is visible as well as palpable and a broadening of the interval between the medial canthi is present. The grandfather of this child, but no other

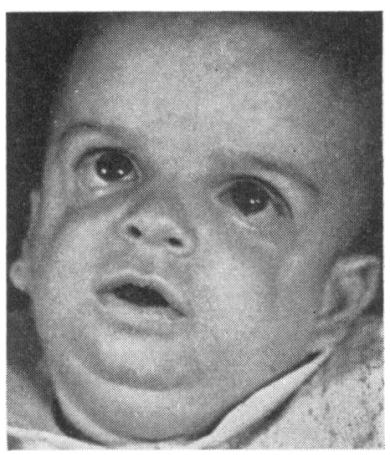

Fig. 12.-Case 6. member of the family, shows flattening over the zygomatic bones without eyelid defect but with deformities of the external ear and external auditory meatus.

Case 7. R.F., aged 28, is the only member of his family showing a congenital abnormality; from birth there have been mere nodules of skin and cartilage representing the auricles; both external auditory meati are absent. Although there is considerable deafness he can carry on a reasonable conversation with the help of lipreading and can understand what is being said on the radio. Apart from his deafness he is normal,

Case 8. B.R., aged 11, shows malformation of his right ear, deformity of the helix, antihelix and lobule with absence of the tragus and external auditory meatus. At an exploratory and reconstructive operation in 1951, it was reported that the anterior and inferior walls of the external auditory canal were missing, also the tympanic ring; the incus was the only middle-ear structure that could be identified.

Case 9. In R.A., aged 14, the left ear shows absence of the tragus and microtia, and there are two tiny accessory auricles; the right ear was markedly deformed at birth with absence of the auditory canal; hearing is diminished, more so on the right side where a conversational voice is heard at $6-8 \mathrm{ft}$. in contrast to $16-18 \mathrm{ft}$. on the left.

Case 10. E.M., aged 4 (Figs. 13 and 14), is a deafmute; the striking features in his appearance are the very wide

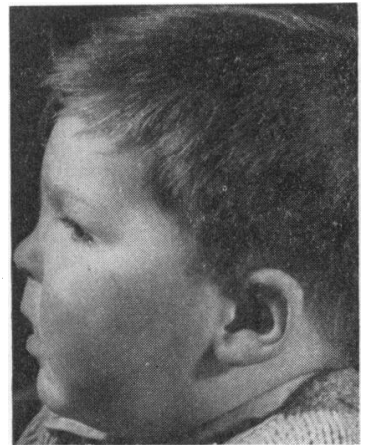

Fig. 13.-Case 10 .

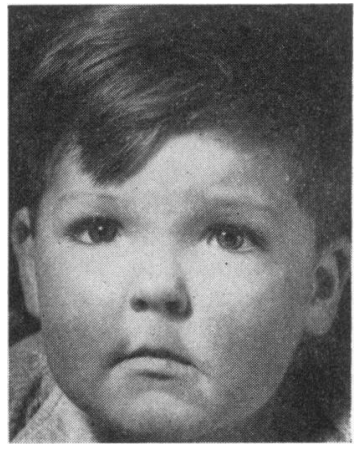

Fig. 14.-Case 10. 
nasal bridge, the different colour of the irises, one blue and the other brown, a narrow palatal arch rising very steeply on either side but showing no cleft and a narrowness or 'pinching' of the nostrils and upper lip region. In the middle of the hair line over the forehead are a few white hairs; this white forelock, like the congenital deafness, is a marked feature in his ancestry; his mother, who declined to be photographed, is congenitally deaf and also had a white forelock when younger but her hair is now all white; she shows no hypertelorism but the frontonasal angle is nearly a straight line. The pedigree chart (Fig. 15) reveals that two brothers of the mother each have a white forelock and congenital deafness and that her father, although not deaf, had the characteristic forelock. No details are available regarding the cause of the 'wasting' in the three brothers and one sister of the mother who all died during their first year. The child's father is only partially deaf probably as a result of middleear disease in childhood.

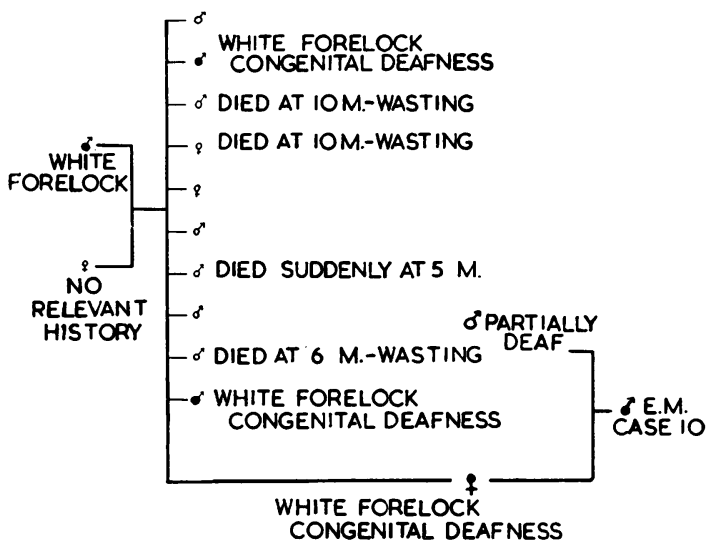

FIG. 15. Pedigree chart of case 10.

Case 11. D.S., aged $5 \frac{1}{2}$ (Fig. 16) is also deaf-

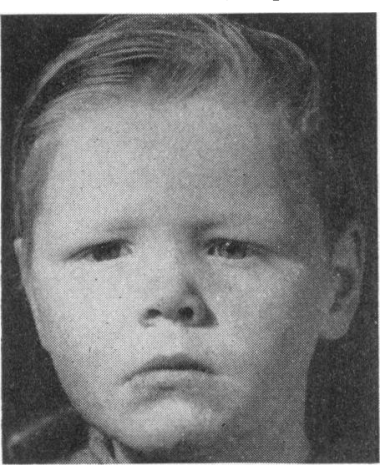
mute and is suspected of being mentally backward. There is an antimongoloid obliquity of the palpebral fissures and his mother volunteers the information that he 'does not weep with his left eye'. This can be due only to hypoplasia of the lacrimal gland on that side. There is no family history of deafness or congenital abnormality.

Fig. 16.-Case 11.

\section{Embryology of the First Visceral Arch}

Figure 17 shows the contributions to the face of the first (mandibular) arch and its maxillary process

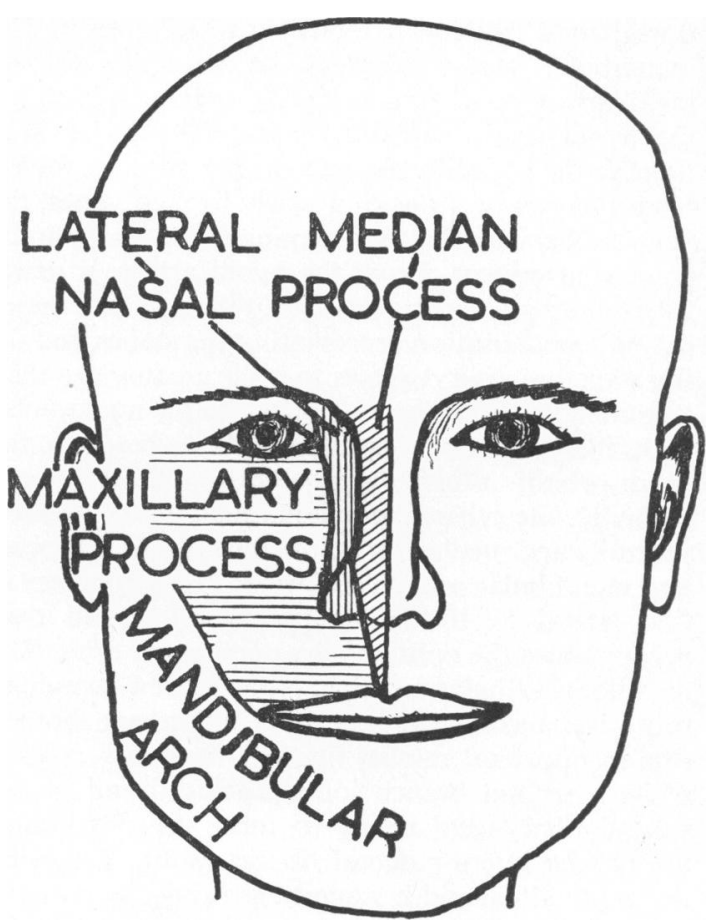

FIG. 17.-Contribution of mandibular arch to structure of face.

and of the frontonasal process. The external auditory meatus is the persistence of the posterior end of the first ectodermal groove while the middle ear and the auditory (Eustachian) tube represent the first, and possibly part of the second, endodermal pouch. Of the pinna, only the tragus and the area immediately around it derive from the first arch, the remainder from the second arch (Wood-Jones and I-Chuan, 1934). The dorsal ends of the first (Meckel's) and second (Reichert's) cartilages provide the ear ossicles, the incus and malleus from the first, the stapes from the second. Although the pterygoquadrate cartilage (part of Meckel's cartilage seen in lower vertebrates) cannot be identified in the human embryo, two cartilaginous masses adjoining the primitive base of the skull are believed to be derivatives, namely the cartilaginous models and later the centres of ossification for the greater and lesser wings of the sphenoid bone. That for the greater wing is supplemented at a later stage by an intramembranous centre of ossification and the same is probably true for the lesser wing. Tandler (1902) and Padget (1948) have described the development of the vascular supply to the first visceral arch and its environs: after the disappearance of the first and second aortic arches, the blood supply of this region is left to small mandibular arteries arising on either side from the 
dorsal aorta (the future internal carotid artery). The mandibular artery confines its activities to the maxillary process (the primitive maxillary artery); the hyoid artery supplies the second visceral arch tissues; the mandibular arch proper receives blood from the ramifications of a newly formed vessel, the ventral pharyngeal artery running forwards from the truncus arteriosus. From the hyoid artery, a newly formed vessel turns forwards through the mesodermal condensation representing the stapes and (as the stapedial artery) grows to a far greater size than its parent vessel; it then advances on the mandibular arch, thereafter dividing into two branches, one, the supra-orbital division proceeding dorsally and cranially, the other, the maxillomandibular division ventrally and medially towards the maxillary process and mandibular arch. The former division passes at first lateral to the trigeminal ganglion and then accompanies the ophthalmic artery to the orbit. The maxillomandibular vessel replaces the now dwindling primitive maxillary artery by sending one branch (the infra-orbital ramus) into the maxillary process while a second branch joins the distal end of the ventral pharyngeal artery to form the mandibular artery (the inferior dental of the adult). Ventrally, the external carotid is already growing towards the mandible and distributing on the way its more proximal branches like the lingual and the facial. Finally it joins the bifurcation of the maxillomandibular artery, takes over its two branches now called inferior dental and maxillary arteries, reverses the flow of blood in the proximal part of the maxillomandibular vessel transforming it into the proximal part of the middle meningeal artery, the distal and main part of which is derived from the supra-orbital division of the stapedial. At the point where it arises from the hyoid, the trunk of the stapedial begins to narrow becoming the superior tympanic branch of the middle meningeal artery. The original hyoid artery persists as the tiny carotico-tympanic artery. In his article Padget (1948) provided an explanation of why there should sometimes be a branch from the anterior division of the middle meningeal artery anastomosing with the ophthalmic artery or even giving origin to the lacrimal and other orbital branches; an ophthalmic branch can be traced to the eye from the supra-orbital division of the stapedial to assist in the supply of the eye and orbit; later the terminal part of the vessel is annexed by the future definitive artery and used as its lacrimal or other orbital branches.

\section{The Etiology of the First Arch Syndrome}

The detailed anatomy of Case 1 showed marked vascular anomalies and, in spite of a well-known range of 'normal' variation in such vessels, these findings are enough to incriminate the arterial system in the production of hypoplasia of the zygomatic bone, if not as the original cause then at least as an important intermediary. Only one reference can be traced in the literature to a defect of the first visceral arch region associated with a vascular anomaly: Tomes (1872) described a mandible showing marked hypoplasia of the left body and ramus with no inferior dental foramen and consequently no mental foramen on that side, 'the vascular supply of this side of the jaw was derived from several small vessels entering the front of the jaw on its inner and outer aspects'. Tomes compared his with a similar specimen described by his father 11 years before; there the canal for the inferior dental artery "was very small and did not emerge at a mental foramen but was lost in the bone'.

From the description given above of the normal blood supply of the first arch it is clear that, in the interval (third to fifth week) between the disappearance of the first aortic arch and the full development of the external carotid artery, the first visceral arch has a hazardous existence, dependent during that time on the relay of three successive vessels, the remains of the first aortic arch, the stapedial artery with its branches and the external carotid artery and on some split-second timing on their part as one relinquishes and the next adopts the supply of that region. Before considering the numerous mishaps which may occur at this time, it is as well to recall the effect of obliteration of any large artery during adult life; provided the patient is young and healthy, arterial anastomoses with adjacent vessels can compensate for the injured artery and within a relatively short time the tissues are receiving adequate nourishment for their needs at rest but they may have to wait an appreciable period before full activity is possible. Compensatory anastomoses will be as active during embryonic life and survival will be as easily assured. These tissues, however, are not at rest; they are seething with an activity less obvious than muscular contraction but far more vital to themselves, namely growth and differentiation which are known to have a high utilization of oxygen and other nutriments.

Far too many hitches may occur in the three weeks so critical to the first visceral arch region for each to receive adequate discussion here, and only a few with their consequences will be mentioned. The stapedial artery which, after all, is a phylogenetically labile vessel and therefore likely to vary, may be very poorly developed; this implies a late start, an inadequate flow of blood and possibly an early involution and if no vessel contemporary with it or 
its branches seeks to help, the maxillary process would find itself without blood after degeneration of the primitive maxillary artery; the mandible would be inhibited in its growth when the time came for the ventral pharyngeal artery to disappear; the supraorbital ramus of the stapedial artery struggling to supply the tissues of the side of the head may be unable to assist the primitive ophthalmic vessel with the normally profuse circulation to the eye and the orbit; poor development of either branch of the maxillomandibular division may be sufficient to prevent death of the tissues in the maxillary process and the mandibular arch but barely enough to allow normal growth, while, unless the external carotid artery reaches this region before the stapedial degenerates, the same results may follow as from an inadequate supply by that artery.

All the compensatory anastomoses may develop in response to such a serious defect as a poorly developed stapedial artery and consequently no evidence of any abnormality may be apparent in later life. On the other hand a dilatory response by one of the neighbouring vessels may result in a relatively short but nevertheless crucial period of malnutrition in a region normally supplied by the stapedial. Juggle with these possibilities and it becomes perfectly clear how failure of one vessel (the stapedial) to play its full part in normal development may result in complete chaos in the subsequent development of the first visceral arch and its derivatives, or perhaps only focal derangements such as inhibition of growth in the maxilla, mandible or ear, or, if conditions at the time happen to be particularly favourable, no perceptible abnormality.

Objections to this explanation may be raised on the grounds that these abnormal events take place between the third and fifth weeks, an appreciable time before any sign of an ossification centre appears in the mandible or maxilla (sixth week) or before the appearance of the hillocks representing the pinna (also sixth week). To cause an upset in initial bone formation, however, a lapse in the maintenance of an adequate blood supply need not occur at, or immediately before, the stipulated time of appearance of the ossification centre; the latter phenomenon is merely a phase in a series of reactions which began some time previously and interference with the blood supply to the region at an earlier date may give rise to an abnormality which is only apparent later.

\section{Genetics of the First Arch Syndrome}

There are too many instances recorded of transmission through several generations for the syndrome to be explained in any other way than by hereditary factors: Debusmann (1940) found 10 members in three generations of one family, Straith and Lewis (1949) described the variations in the syndrome occurring in a mother and her four children, the father having normal features; affected brothers were reported by de Lima and Montiero (1923); a mother and daughter by Berry (1889) and a father and two daughters by Isakowitz (1927); the father of Case 1 described here has a hare lip; Case 10 reflects the features presented by his grandfather and the cases of deafmutism in one family reported by McKenzie (1958) have prototypes in their mother, father and four paternal uncles. Franceschetti and Klein (1949) concluded from their review that mandibulofacial dysostosis was hereditary.

Whether the gene responsible for the syndrome is recessive or dominant may be judged from the incidence of the syndrome; having no relationship to sex or to consanguinity, it must be regarded as dominant although there, too, modifying factors exist, such as the lapse of the syndrome in the second generation followed by its re-appearance in the third, and the many different guises it assumes in its history. These characteristics depend on the expressivity, penetrance and the specificity of the gene concerned. Expressivity is (a) the activity of the gene itself which depends on the quantity of some substance produced by it in initiating the reaction for which it is responsible as well as $(b)$ its activity in relation to the rest of the genes and to the environment (Waddington, 1939). 'Different genes vary greatly in their response to particular environmental changes' (Gates, 1946). Penetrance is a measure of the frequency with which the characteristic features of a gene appear in the carrier while its specificity refers to the kind of effect rather than to the amount.

In this syndrome there is the unique opportunity not only of displaying the morphological sequences which lead to the anomalies in the child but also of explaining the variable expressivity and specificity and moderate penetrance of the gene. The gene, we must presume, is responsible for the maldevelopment or even suppression of the stapedial artery while the compensatory processes (anastomoses) will provide the degrees of penetrance, although other factors must be sought to explain the variability of the compensatory reactions. The results of experimental teratology can, at least partially, solve this problem. Since the time of Saint-Hilaire (1826) it has been well known that anomalies may be produced in chicks by abnormal environment such as shaking the eggs or covering them with varnish. Dareste (1891) and Féré (1899) furthered these experiments while Stockard (1909) and Spemann (1938) exploited the possibilities in the amphibian, but it was not until Hale (1935) showed that anophthalmos and cleft palate occurred 
in pig embryos when the sows were fed on vitamin-Adeficient diets that the production of congenital anomalies in mammals became a common experimental procedure. Many teratogenic agents have since been used, e.g., riboflavin deficiency (Gilman, Perry and Hill, 1952; Nelson, Baird, Wright and Evans, 1956), folic acid deficiency (Thiersch, 1952; Nelson, Asling and Evans, 1952), pantothenic acid deficiency (Giroud, Lefebres, Prost and Dupuis, 1955) and ionizing radiations (Wilson and Karr, 1951; Wilson, Jordan and Brent, 1953). Ingall's (1952) remarks concerning the multiplicity of these experiments adequately sum up the present position: 'From the welter of investigations has come an evergrowing list of teratogenic agents ... As the number rises, however, the question of specificity seems to become less important than dosage and timing of the agent used. The very diversity of teratogenic stresses and agents suggests that any substance that can kill can induce abnormal growth when acting in critical dosage at an appropriate moment of development'.

One of the most vulnerable regions for congenital abnormalities in these experimental animals is that of the first visceral arch, e.g., micrognathus, cleft lip, cleft palate, microphthalmos and anophthalmos, while the only histological investigation after deficient diets in pregnancy was carried out by Giroud, Lefebres, Prost and Dupuis (1955) on deformed limbs; they reported that arrest of the blood circulation in the dilated marginal veins (of the limbs) had occurred. The vascular endothelium had then disappeared and the coagulated blood had come in direct contact with the tissues'. Not only is it possible then to produce a condition like the first arch syndrome but it also appears from experimental procedures as well as anatomical findings that teratogenic effects are mediated through the vessels of the part concerned and, since the blood vessels of the first visceral arch normally provide it with a rather hazardous existence at one period, it is not surprising that this region is among the most vulnerable.

It is not suggested from such findings that the first arch syndrome is caused by dietary deficiency or conditions akin to the experimental procedures, for these were extreme and unlikely to occur naturally. It is enough to postulate a gene or genes as the initial factor inhibiting or even preventing the development of the stapedial artery, but the compensatory anastomoses of the surrounding vessels in such an emergency call for unusually large supplies of nourishment; the normal or minimal amount for normal development is unlikely to allow for compensatory reactions. The result, then, will be inhibition of growth in the area supplied by the faulty stapedial artery and its branches. The penetrance of the gene causing the first arch syndrome therefore depends on the nutritional state and diet of the mother during the first few weeks of pregnancy, even if the diet is minimal or 'adequate' the child may be abnormal because only an excellent nutritional state can successfully prevent the appearance of the anomaly. The expressivity and specificity of the gene, on the other hand, depend on the details and timing of the maladjustments occurring among the vessels concerned.

\section{Discussion}

The inherent tendency for improvement in the shape and development of the mandible seen in Case 5 and in children with the Pierre Robin syndrome requires further explanation. Throughout the normal development, which comprises not only an orderly progression of morphological changes but also a similarly regulated sequence of chemical reactions, there is a precise interval of time allotted to each item of growth or differentiation and all are closely interwoven. The growth and differentiation of an organ or tissue postponed beyond its normal period of activity will be proceeding under the stresses of an inimical environment, and the later the attempt is made the more it is likely to be suppressed entirely. Genetic influences or environmental factors, as we have seen, may inhibit any developmental process and prevent its completion or even its commencement within the specified time, and this initial setback will be perpetuated in successive stages of development in the organ or tissue in spite of attempts to make up the leeway. The growth of an organ or part of the body like the mandible may be compared with the journey of a long-distance express train after it has been delayed in the early part of its trip; the normal schedule provides it with immediate clearance at all junctions and signals but, if it be late, then it must contend with the demands of other trains which are on time and must take precedence over it. The delay is thus maintained if not aggravated, but the train will eventually reach its destination after facing the hazards of an unscheduled journey.

In Case 5 and in the Pierre Robin syndrome an early upset in the nutrition of the mandible and possibly of the other parts of the face was sufficient to retard growth but not to cause irreparable damage or prevent recovery; during the last few weeks of pregnancy the normal intra-uterine pressure was enough to distort this under-developed bone struggling under adverse conditions to make up its leeway. Only after birth (during the first year or two of life) does the mandible have the freedom to complete its development, correct the deformity and 
assume its genetically determined shape. The same explanation will suffice for deformities such as clubfoot, but several bones are involved in these cases and structural adaptation of unaffected tissues usually occurs before birth.

In Case 2 where an infantile mandible and defective zygomatic arches were associated with unexplained anomalies of the limb bones, there had been, during the third to fifth week of intra-uterine life, a nutritional disturbance influencing the first visceral arch, already affected by an abnormal stapedial artery, and leaving in its wake the characteristic features of the syndrome. This superimposed nutritional upset, however, also interfered with the initial capillary growth in the limb buds, inhibiting their development without altering the structural pattern. Whether there had been a distortion of the limbs caused by intra-uterine pressure and visible at birth is unknown but there is normally a distinct curvature in the legs of the newborn infant. Although during normal postnatal development, the bones are adequate to withstand the weight of the child, in this case the epiphyses and their newly formed bone were prematurely subjected to strenuous activity which was not favourable to processes striving to make up lost ground; the metaphyseal region, then, like the mandible in Case 5 before birth, yielded to the forces applied to it, forces which would not have affected normally growing bone. It should be noted also that not only are the bones of the lower limbs more distorted than those of the upper limb because of weight-bearing but also that the regions showing the curvatures are at the more actively growing ends of the bones, namely around the knee and at the wrist joint. In all likelihood, if the activities and weight of the child had been restricted up to, say the age of 8 or 10 (there are obvious difficulties and objections to such a course), these aspects of the child's development would have been in step with the growth of the limb bones and no deformity would have resulted. This is borne out by the history that the curvatures of the limbs did not increase markedly, if at all, in his teens.

Superficially, the cause of hypertelorism seems remote from the first visceral arch; closer examination, however, shows that the presenting feature, the wide interocular distance, is really a compensatory effect for poor development of the maxillary process, an effect seen also in cases of cleft lip and palate. Greig's first case showed poorly developed maxillae, unusually small squamous temporals and greater wings of sphenoid (all in first arch territory). In Case 10, the frontonasal process had spent itself in spreading or expanding laterally at the expense of its downward development and thereby provided an extremely high, slot-like palatal arch; no cleft had occurred because the palatal processes of the maxillae had succeeded in joining the nasal septum before being drawn upwards by the delayed growth of the over-taxed frontonasal process. The pinched appearance around the nostrils and upper lip arose from the same cause. A straining of the nutrition in the frontonasal process in such cases may account for the white forelock immediately above it, while variations in the blood supply to the two eyes could easily be the cause of their being different colours.

Fisch and Renwick (1956) and McKenzie (1958) showed that congenital deafmutism may occur in association with first arch deformities and the latter author demonstrated the middle ear origin of the condition. On clinical examination there is no evidence of any defect within the middle ear, hence the presumed normality of the ossicles; but the incus may be at fault because of its origin from the first arch (Meckel's) cartilage while the stapes, although a remnant of the second (Reichert's) cartilage, has the stapedial artery traversing it in the early stages of its development. The exact site of the abnormality, however, will have to await confirmation, although Wilson (1955) states that the ossicles are seldom abnormal in an otherwise normal ear but, if so, it is usually the stapes which is at fault.

\section{Summary}

Eleven cases illustrating the clinical features of eight different types of congenital anomaly or syndrome affecting the head and neck are described along with the relevant literature on each.

From a consideration of the clinical features, the anatomy described in several cases, the embryology of the first visceral arch and its environs, especially the development of the blood vessels, and, from an examination of the hereditary features, it is claimed that all the anomalies mentioned comprise one hereditary syndrome (the 'first arch syndrome') caused by a dominant gene or group of dominant genes with variable specificity and expressivity and with only a moderate degree of penetrance.

I am indebted to Professor R. D. Lockhart for his advice, help and interest during the preparation of this paper; and to the following for allowing me access to their case notes: Dr. George Swapp, Aberdeen (Case 2); Mr. A. B. Wallace, Royal Hospital for Sick Children, Edinburgh (Cases 3, 4 and 6); Dr. P. MacArthur, Royal Northern Infirmary, Inverness (Case 5); Mr. I. S. D. Thomson, Royal Aberdeen Hospital for Sick Children (Cases 8 and 9); and Dr. Dorothy Younie, Senior Assistant M.O.H., Aberdeen (Case 10).

REFERENCES

Altmann, F. (1950). Arch. Otolaryng. (Chicago), 51, 852

Berry, G. A (1889) Roy. Lond ophthal. Hosp. Rep. 12 255

Collins, E. Treacher (1900). Trans. ophthal. Soc. U.K., 20, 190. 
Dareste, C. (1891). Recherches sur la Production Artificielle des Monstruosités, 2nd ed. Paris.

Davis, A. D. and Dunn, R. (1933). Amer. J. Dis. Child., 45, 799.

Debusmann. (1940). Arch. Kinderheilk., 120, 133.

Ely, R. C. and Farber, S. (1930). Amer. J. Dis. Child., 39, 1167.

Féré. (1899). Cinquantenaire de la Société de Biologie, Vol. Jubilaire, p. 360 Fisch, L. and Renwick, T. K. (1956). The Teacher of the Deaf, 54,

Franceschetti, A. and Klein, D. (1949). Acta ophthal. (Kbh.), 27, 143.

Gates, R. R. (1946). Human Genetics, Vol. 1. New York.

Gilman, J. P. W., Perry, F. A. and Hill, D. C. (1952). Canad. J. med. Sci., 30, 383.

Giroud, A., Lefebres, J., Prost, H. and Dupuis, R. (1955). J. Embryol. exp. Morph., 3, 1.

Greig, D. M. (1924). Edinb. med. J., 31, n.s., 560.

Hale, F. (1935). Amer. J. Ophthal., 18, 1087.

Herman. (1936). Bull. Soc. belge Ophtal., 73, 60.

Hövels O. (1953a), Z. Kinderheilk., 73, 532.

- (1953b). Ibid., 73, 568.

Ingalls, T H. (1952) Conference on Prematurity, Congenital Anomalies and Birth Injuries, New York Academy of Medicine, Anomalies anc, 1952 .

Isakowitz, J. (1927). Klin. Mbl. Augenheilk., 78, 509.

Lapage, C. P. (1937). Lancet, 1, 323.

Lenstrup, E. (1925). Acta paediat. (Stockh.), 5, 154.

Lima, J. A. Pires de, and Montiero, H. B. (1923). Arch. Anat. Antrop. (Lisboa), 8, 185.

Linnt, A. van, and Hennebert, P. (1936). Bull. Soc. belge Ophtal. 73, 57.

Llewellyn, J. S. and Biggs, A. D. (1943). Amer. J. Dis. Child., 65, 440.
Lockhart, R. D. (1929). J. Anat. (Lond.), 63, 233.

McEnery, E. J. and Brennemann, J. (1937). J. Pediat., 11, 468.

McKenzie, J. (1958). Brit. med. J. In press.

- and Craig, J. (1955). Arch. Dis. Childh., 30, 391.

Mann, I. (1943). Brit. J. Ophthal., 27, 13.

Nager, F. R. and de Reynier, J. P. (1948). Practica otorhinolaryngologica, Suppl. 2, Vol. 10.

Nelson, M. M., Asling, C. W. and Evans, H. M. (1952). J. Nutr., 48,61 .

_- Baird, C. D. C., Wright, H. V. and Evans, H. M. (1956). Ibid., 58,125 .

Padget, D. H. (1948). Contr. Embryol. Carneg. Instn., 32, 205.

Robin, P. (1934). Amer. J. Dis. Child., 48, 541.

Saint-Hilaire, E. G. (1826). Journ. Comp. du dict. de sc. Med., 24, 256

Spemann, H. (1938). Embryonic Development and Induction. London.

Stockard, C. R. (1909). J. exp. Zool., 6, 285.

Straith, C. L. and Lewis, J. R. (1949). Plast reconstr. Surg., 4, 204.

Tandler, J. (1902). Morph. Jb., 30, 275.

Thiersch, J. B. (1952). Amer. J. Obstet. Gynec., 63, 1298.

Tomes, C. S. (1872). Trans. odont. Soc. G.B., 4, 130.

Waardenburg P. J. (1932). Das menschliche Auge und seine Erban-

lagen. Haag.
Waddington, C. H. (1939). An Introduction to Modern Genetics. London.

Walker, D. G. (1956). Unpublished M.D. Thesis. Dublin.

Wilson, T. G. (1955). Diseases of the Ear, Nose and Throat in Children. London.

Wilson, J. G., Jordan, H. C. and Brent, R. L. (1953). Amer. J. Anat., $92,153$.

- and Karr, J. W. (1951). Ibid, 88, 1.

Wood-Jones, F. and I-Chuan, W. (1934). J. Anat. (Lond.), 68, 525. 